\title{
Promoting Structured Participation for Competitiveness in Services Companies
}

\author{
Jesús García-Arca (D) J. Carlos Prado-Prado (D), Arturo J. Fernández-González \\ Grupo de Ingeniería de Organización (GIO), Escuela de Ingeniería Industrial, Universidad de Vigo (Spain) \\ jgarca@uvigo.es,jcprado@uvigo.es,ajfdez@uvigo.es
}

Received: November 2017

Accepted: December 2017

\begin{abstract}
:
Purpose: To identify the main drivers that facilitate the successful deployment of a participation program aimed at improving competitiveness, as a prior step to analyze and discuss the implementation of these drivers in three services companies.

Design/methodology/approach: The selection of the drivers was based on a "content analysis" of recent literature (2007-2017). To test the level of deployment of these drivers, the "case study" technique was chosen. The authors have selected two public transport companies and one bank, which have more than twenty years' experience in the development of participation programs.
\end{abstract}

Findings: From the case studies analysis, we conclude that participation can successfully improve a company's competitiveness, provided that the drivers are developed with this specific aim. Thus, the analysis of these drivers allows to identify some gaps in aspects such as, the extension of participation throughout the company, the methodology adopted in the deployment of participation programs, the organizational structure for monitoring the program tasks, the reward/recognition systems and, especially, the implementation of KPIs for connecting participation and competitiveness.

Research limitations/implications: This paper is based on a review of current literature, the analysis of three case studies, and our own personal experience. Our observations and comments may be qualified by future investigation with an increased sample of companies.

Practical implications: This paper could be of interest to companies due to outlines the drivers that are critical to implementing participation programs focused on competitiveness. This could help companies that are thinking of implementing such programs, or those that are unhappy with their current programs, to re-design their plans in line with their business strategy.

Originality/value: The main contribution of this paper lies in its theoretical and applied approach, analyzing in a comparative and longitudinal way the deployment of the drivers in services companies. This analysis allows the identification of strengths and weaknesses in the implementation of these participation programs focused on competitiveness.

This combined and comparative approach is considered especially novel in the academic and professional world. Likewise, the analysis of companies with a longstanding history in their participation programs is also relevant, particularly, in the services sector.

Keywords: participation, continuous improvement, services companies 


\section{Introduction}

Nowadays, companies must improve their processes to adapt to market demands by providing not only greater diversity and innovation in products, but also lower prices and higher quality and service standards.

Improvements can come from both an investment in new technologies/equipment, and making small changes that would gradually increase performance. This latter option, known as "continuous improvement", requires hardly any investment. It forms the basis of different approaches, such as Kaizen, Lean, TQM or JIT (Prado-Prado, GarcíaArca \& Fernandez-Gonzalez, 2012; Jaca, Santos, Errasti \& Viles, 2012; Lam, O’Donnell \& Robertson, 2015).

Boer, Berger, Chapman and Gertsen (2000) define continuous improvement as "the planned, organized and systematic process of ongoing, incremental and company-wide change of existing practices aimed at improving company performance."

Although "continuous improvement" has been at odds with "innovation", both concepts should be considered as complimentary (Bessant, Caffyn \& Gallagher, 2001; Prado-Prado et al., 2012).

Implementing a continuous improvement program within an organization requires learning and knowledge to apply a system, following a philosophy of change, and the active participation of everyone involved in the processes (Bessant et al., 2001; Prado-Prado et al., 2012; Lam et al., 2015; Psomas \& Jaca, 2016).

Although Board support is fundamental to program design and monitoring, most improvements place at the level of operators and supervisors (Terziovski \& Sohal, 2000; García-Lorenzo \& Prado-Prado, 2002; García-Sabater, Marín-García \& Perelló-Marín, 2012; Jaca, Palpa-Galeano, Viles \& Mateo, 2016; Uhrin, Bruque-Cámara \& Moyano-Fuentes, 2017). Therefore, staff participation in improvements increases their motivation and satisfaction, (Gerhart, 2012; Wang, Thornhill \& Zao, 2016), even as a High Involvement Work Practice. This last statement points out an important relationship between "structured" participation, implementing continuous improvement, and achieving better performance.

However, workers commitment to participation depends on the company's internal culture, but also on the attitude of workers. In this context, Prado-Prado et al. (2012) suggest that there are three types of workers: "devoted" workers, who represent between $5 \%$ and $20 \%$ of the total workforce (they always say yes to any positive proposal or initiative made by the company); "apathetic" workers, who represent the largest group, usually between $60 \%$ and $80 \%$ of the workforce (they are not pro-active, choosing to wait); and finally the "disgruntled" workers, representing between $5 \%$ and $20 \%$ of the total (who always say no to any new proposal or initiative).

Although, there is always a minimum number of "devoted" workers, who are willing to involve in participation program, the challenge for companies is to generate and promote a culture of improvement, knowledge and innovation that would convince the "apathetic", and even the "disgruntled" workers. To achieve this last step in very important the design of the participation program.

\section{Objectives and Methodology}

In this context, this paper has two main objectives: to identify the main drivers that facilitate the successful deployment of a staff participation program, and to analyze the operation and deployment of these drivers in three services sector companies, showing how they can improve competitiveness.

We are interested in the issue of participation in the context of competitiveness because its treatment in literature is limited. Moreover, evidence suggests that not all organizations, especially those in the services sector, have achieved the desired success (Marín-García, Pardo-Val \& Bonavia-Martín, 2008; Sherrer-Rathje, Boyle \& Deflorin, 2009).

Although there are differences between sectors and companies, processes in services companies are characterised by their ability to adapt to client needs, their heterogeneity, their intangibility, and their lower level of standardization, especially when compared with the industrial sector (Fitzsimmons \& Fitzsimmons, 2004; Slack, Chambers, Harland, Harrison \& Jonhson, 2007; Di Pietro, Mugion \& Renzi, 2013). 
We have selected the drivers by carrying out a "content analysis" of recent literature (2007-2017), searching for the combined concepts of participation, continuous improvement (or any other improvement approach) and competitiveness (such as results or performance).

To test the level of deployment of these drivers, we chose the "case study" technique (Yin, 2002). This approach is appropriate when studying managerial processes, because the boundaries between the phenomenon and its context are not clearly evident (participation and competitiveness). In this sense, the collaboration between practitioners and researchers to enrich understanding by means of the Case Study methodology is interesting in operations management (Coughlan, Draaijer, Godsell \& Boer, 2016), particularly, in operations in services companies (García-Arca \& Prado-Prado, 2011).

Thus, we selected two public transport companies and one bank, which have more than twenty years' experience in the development of participation programs.

In order to collect and analyse information, we interviewed the coordinators of the various programs, with the aid of a structured questionnaire which addressed different issues related to the drivers. Following this first data collection phase, we reflected on the results and discussed them with the interviewee, which has served to enrich the discussion section at the end of this paper.

The main contribution of this paper lies in its approach, not only theoretical, but also applied, analyzing in a comparative and longitudinal way the deployment of key drivers in the implementation of participation programs in services companies. This analysis allows the identification of strengths and weaknesses in the implementation of these participation systems focused on competitiveness.

This combined and comparative approach is considered especially novel in the academic and professional world. Likewise, the analysis of companies with a longstanding history in their participation programs is also relevant, particularly, in the services sector.

\section{Drivers for Structuring Staff Participation}

Participation systems can be both group systems (e.g. quality circles, improvement groups) and individual (e.g. suggestion systems) (García-Lorenzo \& Prado-Prado, 2002), although there is no consensus as to which provides better results. Rapp and Eklund (2007) and Marín-García et al. (2008) highlight the benefits of individual systems, especially for their easy implementation. Prado-Prado et al. (2012) or Jaca, Santos et al. (2012) favour group systems, because they consider them to help develop communication, and knowledge, between all hierarchical levels.

Much of the recent literature on continuous improvement and participation systems, employs either case studies (mostly in the industrial sector), or analysis in a geographical or sectorial context. In the services sector, there are some studies in public companies (Arlbjørn, Freytag \& de Haas, 2011; Di Pietro et al, 2013; Neumann, Mothersell \& Motwani, 2015), in distribution companies (García-Arca \& Prado-Prado, 2011; Jaca, Santos et al., 2012), and in the health sector (Anand, Chhajed \& Delfin, 2012; Prado-Prado, Fernández-Pérez \& Mosteiro-Añón, 2013).

A literature review carried out by the authors identifies eight main drivers that facilitate competitiveness' improvement through employee participation based on "continuous improvements" projects (Marín-García et al., 2008; Sherrer-Rathje et al., 2009; Marín-García \& Bautista-Poveda, 2010; García-Arca \& Prado-Prado, 2011; PradoPrado et al., 2012; Jaca, Santos et al., 2012; Jaca, Viles, Mateo \& Santos, 2012; Lam et al., 2015; Jurburg, Viles, Tanco \& Mateo, 2016):

- Commitment of managers. Without clear management support and involve-ment, sooner or later these programs will disappear, since the rest of the organization will interpret them as not being important for the company.

- Key performance indicators (KPIs). KPIs are necessary to measure the impact of each improvement, and to connect participation with competitiveness. These KPIs (and objectives) should not only be confined to direct performance (productivity, costs or quality), but also to participation, via the number of actions or workers involved. This allows for an indirect measurement of how staff motivation evolves, and the development of a culture of improvement. 
- Organizational structure for participation. It serves to support the participation program's design, promotion, and monitoring. Literature features various ways to deploy this structure, whether at an individual level ("facilitators" or "champions"), or at a collective level (teams or committees). Middle management and even union representatives could form part of this structure.

- Methodology. It is necessary to develop the participation program and to implement a culture of improvement and serves to design, monitor, and improve participation programs. The methodology must define not only stages, activities and priorities, but also, frequency, timetables and duration of the meetings.

- Communication. It is essential in order to promote a culture of improvement within an organization, and to increase competitiveness and worker motivation through participation. It can take many forms, such as information boards, magazines, intranet, public presentations, and so on. Achieving good results, and word of mouth, are the most powerful means of communication.

- Training. This training includes both traditional training techniques associated with problem solving and an awareness of improvement and teamwork. Some authors recommend complimenting basic training with "learning-by-doing".

- Resources. They are necessary for proposed improvements to become a reality. A lack of resources available for developing improvements can discourage staff, and reduce their commitment to participation programs.

- Recognition/Reward. This driver has an important impact on staff motivation, and consequently on their commitment to participation programs. Literature differentiates between "reward" (essentially economic), or a "payment in kind", and "recognition" (essentially social), although there is no consensus as to which is more appropriate. Rewards are more common in individual systems.

\section{Cases Analysis}

In this chapter, the analysis of the participation programs in the three companies is developed.

\subsection{Case $\mathrm{A}$}

The first case for analysis is a public transport operator in one of the largest metropolitan areas in Spain, with more than 7000 employees. Some of its participation programs have been in place for over 20 years, with the continued support of different management teams. Currently, the company has three types of systems in place: Working Groups, Suggestions, and Improvement Sessions.

- The Working Groups are the oldest system in place, and comprise of a reduced number of people from the same department. They are formed spontaneously, and work on a voluntary basis with a large degree of autonomy in both their structure and functionality (e.g. time, frequency and duration of meetings) and in their ability to propose, analyze, and implement improvements in their respective department. Workers and at least one member of middle management are encouraged to participate in each group, although there is no specific group leader as such.

- A suggestion system was subsequently launched where any worker could advise of problems with and/or suggest improvements to workplace operation, via an electronic form on the company intranet. Suggestions are then evaluated by each departmental manager.

- The final system in place is the Improvement Sessions. These consist of intensive, typically one-day sessions which take place at the request of one department. They are designed to analyse and resolve a complex or cross-sectional problem within the organisation. Session participants come from the departments affected by the problem, and are usually middle managers, and to a lesser extent, workers and area managers.

Coordination and monitoring of these participation programmes is the responsibility of the "Participation Manager", who in turn is responsible to the department of Human Resources, which is in the top level of company organisation. This manager is responsible for facilitating and coordinating all aspects of the participation experience, acting as a "collector" of all the tasks undertaken in each programme, whether they are implemented or not. 
The development of participation indicators in this case is very basic. These indicators focus especially on the participation level (e.g. percentage of staff involved), and the level of worker satisfaction with the participation program, which is generally rated very highly. However, there are no specific indicators to measure the impact of the implemented improvements on company performance at a tangible level, in terms of costs or productivity.

From the beginning, the company has strived to make the activities and the results achieved through the various participation systems more visible. Thus, the company has a half-day results presentation every 4 months, culminating in an annual participation "celebration" involving workers and the management team. These communication activities are complimented by the company intranet, the corporate magazine, and internal panels.

Operational procedures are not in place within the company for the participation programme. However, the company does offer a voluntary training programme for workers specifically related to the participation programme, including analysis and problem-solving techniques.

Given that participation is voluntary and most of the meetings and group work take place outside working hours, employees are rewarded "in kind" for their participation in working groups through regular draws for weekend trips away. Moreover, the authors of best suggestions, as decided by the head of each department, are also entered in the draw. Participation in Improvement Sessions, however, is not rewarded because they take place within working hours.

Although there is a general budget for rewards, and participation programme communication, any small investments required to implement improvements are channeled directly from each departmental or area budget.

In general, the company believes that the main achievements of the participation programme are improvements related to internal coordination, to safety, to work conditions, and to transport services on offer. The company also acknowledges the stability that results in having a primarily permanent workforce. This creates an environment conducive to involvement, motivation, and participation throughout the company, including workers, middle management and senior management. Overall, around $8 \%$ of the workforce has been directly involved in participation systems. Around 60 groups are opened annually.

\subsection{Case B}

The second case for analysis is a state-owned company charged with the management and maintenance of transport infrastructure throughout Spain. It has over 15000 employees. The company began its staff participation programs over twenty-five years ago and since its inception has had the support and commitment of various management teams. At present, it has three types of systems in operation: Improvement Teams, Improvement Groups, and Best Practices.

The first two systems are the oldest, and have a group basis but differ in origin and composition. Improvement Teams are always management driven initiatives, which are used to unveil problems or improvement opportunities in quality management systems, such as internal audit results, claims, etc. However, the Improvement Groups are formed by one or more workers who wish to address a problem or idea. Around 40 teams or groups are created annually.

The more recently implemented Best Practice system is similar to a suggestion system. An employee (or group of employees) proposes an idea or initiative, which must be accompanied by a simple feasibility or viability study. Depending on the complexity of the issue, an Initiative and Improvement team is set up, which would include those employees who made the initial suggestion.

At an organizational level, the coordination and monitoring of the different participation systems is spread throughout the company. The Quality Committee, which includes representatives from all company departments, forms part of the Quality Division, which in turn answers directly to senior management.

Within this committee, the Participation Sub-Committee meets monthly to monitor the participation program. Senior management regularly participates in this sub-committee, thus highlighting its commitment to the participation systems. 
The Quality Division has a "Network of Facilitators" which are integrated in each department. These facilitators coordinate with the departmental heads, to support the participation systems either by addressing the needs of each group or team (e.g. meeting space, contact with a supplier, etc), or by promoting participation. Each facilitator is answerable to both the departmental manager, and the Quality Committee.

The company is committed to developing performance indicators for both the activity of participation systems, such as the percentage of staff involvement or actions implemented, as well as the results achieved, particularly savings. However, objectives have only been established for participation activity, and these are usually met and exceeded. But the company does not carry out worker satisfaction surveys regarding the operation of newly implemented systems or related activities.

The whole organization is informed of the activities and the results achieved through the participation systems by means of an internal company magazine and a special section on the corporate intranet. In addition, team and group activities are recognized at an annual event where they present the results achieved to colleagues and senior management.

Furthermore, operational procedures are in place for these participation systems, thereby integrating them as improvement elements in the company's Quality Management System structure. In fact, the company believes that implementing these programmes has allowed them to coordinate the deployment of their Quality Management System, in accordance with ISO 9000 and the EFQM model.

In this context, a voluntary training program is in place which relates specifically to the tasks required in the participation systems, and offers simple analysis and problem-solving techniques.

Participation in working groups is rewarded in kind by means of entering an annual draw for three travel-related prizes. The Quality Committee selects the best examples of participation, and all workers who enter this draw receive a diploma and a small gift from management. Those who are preselected by the Committee will later participate more directly in the annual event, presenting results, in order to recognize participation.

There is no general budget for the participation program, therefore each departmental or area budget must cover any costs incurred.

Participation program has shown some partial impact on business performance by means of reduced costs, improved quality and innovation. It has also impacted indirectly in terms of improved coordination and internal cooperation. In addition, having a largely permanent workforce has helped significantly. Since their inception, approximately $5 \%$ of the workforce has been involved in some participation program.

\subsection{Case $\mathrm{C}$}

The final case is one of Spain's biggest banks, which employs more than 10,000 people throughout the country. Despite the recent crisis in Spain's financial sector, this bank has successfully managed to weather the storm.

A staff participation program arose from senior management's desire to introduce alternative management strategies that would actively contribute to reducing costs, improving productivity and motivating staff. A suggestions system was launched over 30 years ago. Subsequently, in 2002, a Quality Management System was developed and implemented, as well as an Improvement Groups program; both of which are currently in operation.

The suggestions system works via an online platform on the corporate intranet which redirects the idea to the department of its proponent for a preliminary evaluation. The response time tends to be slow because many staff suggestions relate to departments other than their own.

Improvement Groups are made up of workers from the same department. Group membership is usually permanent, with little rotation; so, they form what is known in literature as a Quality Circle. These groups do not follow strict operational procedures, so in practice they are free to decide on the frequency, duration and time of meetings. 
Standard operational procedures are, however, in place for the suggestion system, within the Quality Management System framework. In fact, the suggestion system has its own specific budget, while any Improvement Group expenses are informally covered by each departmental budget.

The majority of Working Groups operate from the bank's head office, although the large number of employees operates in the branch network. This is because head office staff has more flexible working hours than branch staff, thereby making it easier to schedule group meetings. As a result, teams work more on analyzing problems, and designing possible improvements, than on implementation. This may be because most processes require IT support and therefore many improvements require software changes.

The organizational structure for managing the participation program is decentralized. All company areas or departments are represented on the Quality Committee, which plans and monitors the development of the participation program, and issues official notification regarding activities and results via the company intranet. Each committee member is responsible for deploying this participation strategy in his department. Senior management also participates in the Quality Committee.

There is no specific participation training, although there is general quality management training.

There are operational indicators and objectives for the suggestions system relating to the participation and implementation rate, as well as the impact and estimated savings of implemented improvements. For example, more than $10 \%$ of the workforce participates in the suggestions system. However, there are no indicators or objectives in the participation program for Improvement Groups, although each department has objectives and indicators as set out in their own strategic plan, which in turn could be achieved by launching improvement groups, among other measures.

Likewise, there is no system in place to measure employee satisfaction with the implemented participation systems.

With regard to rewards and recognition for participation in these systems, only in suggestions systems, employees can avail of some financial incentive depending on the suggestion's economic impact. Employee suggestions are initially assessed by the respective departmental heads, who in turn forward the best suggestions to the Quality Committee.

Employee participation is recognized at an annual "Quality Day" event where all members of the Improvement Groups, as well as any employees who have made suggestions present their results to the senior management team.

The implementation of the participation systems has improved the intangible results, such as a better working environment and a better staff coordination and motivation. It has also facilitated the development of their quality management system. However, it has not managed to clearly connect the actions implemented through participation systems with business results, especially in terms of cost reduction or improvements in quality of bank services.

\section{Lessons Learned}

Our case study analysis shows variation in the development of participation programs in each of the three companies, with the second company under study, possibly being the most structured and focused on enhancing competitiveness.

Participation should have a dynamic structure, and be able to adapt quickly in order to surprise staff and maintain enthusiasm throughout an organization. In fact, implementing and developing participation systems should be considered an evolutionary process, conditioned by how each company change over time to interpret and assess markets' needs and trends.

Management of all three companies try to show the same initial interest for participation programs, by being actively involved in their operation, albeit to different degrees and in different ways. In fact, management involvement in these programs increases participation, and proves to be especially motivating for "devoted" workers.

It is our view that the multifaceted origin of the problems or improvements demands a shared approach, and consensus among staff coming from different hierarchy and responsibility. Therefore, the contributions of working 
groups should be at the heart of these participation programs. Logically, as this paper shows, this base can be enriched by individual systems.

Although all three companies demonstrate their bet with these group systems, they must work more towards having cross-sectional groups. In the first two companies, group members come from only one department, in the third company, the situation is worse, since not only do group members come from the same area or department, but they are concentrated solely in the head office, without any connection with the local branch network.

Furthermore, the standard operating procedures for these groups could be improved. The first company enjoys broad, almost chaotic, autonomy, which hinders their drive towards competitive improvement. To date, the company has kept these systems in place as a means for basic communication and worker motivation. In the third company, groups have no closing date, without clear objectives or a defined methodology; procedures are in place for suggestions only. This can be discouraging and tiring for employees. Only the second company has standard operating procedures in place for all participation systems, which they try to align with their competitive strategy.

However, as the organizational base for an improvement program, working groups alone are not enough. A decentralized cross-sectional organizational structure is also recommendable. This would help design and monitor an improvement process, in line with the indicators and objectives as set out in a business strategy. The last two companies have opted for this type of structure, in the form of a committee within their quality management systems. This system is more pronounced in the second company, through their facilitators' network.

However, in the first Company only one person is responsible for coordination and promotion of the participation program. This makes a decentralized cross-sectional management more difficult.

One of the main problems that we identified in the participation programs is the limited definition of KPIs and objectives. All three companies are struggling to orient participation program actions towards improved business results. In fact, even the second company, which has found some direct results through implementing participation programs, has not achieved totally this goal in terms of competitiveness improvement. Although the last two companies have the best decentralized, cross-sectional, organizational management, they are still struggling, and need a specific measuring system to connect participation and competitiveness. Of course, not having this measuring system hinders the drive towards competitive improvement, as mentioned above.

Hence, we believe that participation should not be considered as an isolated and spontaneous process, but rather as a process clearly connected to the company strategy, and actively contributing to improved competitiveness.

However, it is not enough to implement participation programs that are only devoted to solve problems or achieve improvements linked to competitiveness. It is also important to include problems and improvements which workers themselves consider important, even if they are not directly connected to direct results. This can particularly improve "devoted" worker commitment and motivation, but also "apathetic" and "disgruntled" workers.

Recognition contributes particularly to worker motivation. The first two companies combine various systems to increase worker commitment and motivation, such as internal communications, regular public sessions, but also incentives "in-kind" like holiday draws, depending on the type of program. Though in the third company, potential incentive "in-kind" only applies to the suggestions system, which can discourage group participation.

On the other hand, regarding the noted drivers, none of the companies have problems with participation program in deployment of the training, the communication, or the resources, though each works within its own guidelines.

Either way, improving processes through staff participation helps to rationalize resources (for example, raw materials, energy, and workers' hours), reducing waste production. This leads to a greater economic and environmental sustainability. Likewise, participation should be considered as a key aspect for implementing sustainability from a social point of view, given that it improves work conditions and worker motivation; as well as contributing to improved competitiveness.

In a study by Fernández-González, Fernández-Pérez and Prado Prado (2014), on the main models and standards that apply to developing sustainable development, they conclude that there are no specific references to staff participation for improving competitiveness. This comment indicates a potential area for future research. In this 
context, none of the three companies have integrated their workers in designing and improving participation programs. In fact, only the first company asks its workers about their satisfaction with the operation of such programs.

\section{Conclusions}

Following a review of the literature on staff participation, continuous improvement and competitiveness, we can summarize the various drivers required for the successful deployment of a participation program, particularly in the services sector.

The analysis of these drivers in the three companies allows to identify some gaps in aspects such as, the extension of participation throughout the company, the methodology adopted in the deployment of participation programs, the organizational structure for monitoring the program tasks, the reward/recognition systems and, especially, the implementation of KPIs for connecting participation and competitiveness.

This paper could be of interest to both the business and academic community, given that it outlines the drivers that are critical to implementing these programs, and in an applied sense, how they can be improved and oriented towards actively contributing to improving competitiveness. This could help companies that are thinking of implementing such programs, or those that are unhappy with their current programs, to re-design their plans in line with their business strategy.

This paper is based on a review of current literature, the analysis of three case studies, and our own personal experience. Our observations and comments may be qualified by future investigation; consequently, we are working on new applied research with an increased sample of companies.

\section{Declaration of Conflicting Interests}

The authors declared no potential conflicts of interest with respect to the research, authorship, and/or publication of this article.

\section{Funding}

The authors received no financial support for the research, authorship, and/or publication of this article.

\section{References}

Anand, G., Chhajed, D., \& Delfin, L. (2012). Job autonomy, trust in leadership, and continuous improvement: An empirical study in health care. Operations Management Research, 5(3-4), 70-80. https://link.springer.com/article/10.1007/s12063-012-0068-8 https://doi.org/10.1007/s12063-012-0068-8

Arlbjørn, J.S., Freytag, P.V., \& de Haas, H. (2011). Service supply chain management: A survey of lean application in the municipal sector. International Journal of Physical Distribution \& Logistics Management, 41(3), 277-295. https://doi.org/10.1108/09600031111123796

Bessant, J., Caffyn, S., \& Gallagher, M. (2001). An evolutionary model of continuous improvement behavior. Technovation, 21(2), 67-77. http://www.sciencedirect.com/science/article/pii/S0166497200000237 https://doi.org/10.1016/S01664972(00)00023-7

Boer, H., Berger, A., Chapman R., \& Gertsen F. (2000). CI changes. From suggestion box to organisational learning. Continuous improvement in Europe and Australia. Ashgate, Aldershot. https://www.researchgate.net/publication/242713487 CI Changes From Suggestion Box to Organisational

Coughlan, P., Draaijer, D., Godsell, J., \& Boer, H. (2016). Operations and supply chain management: The role of academics and practitioners in the development of research and practice. International Journal of Operations \& Production Management, 36(12), 1673-1695. http://www.emeraldinsight.com/doi/full/10.1108/IJOPM-11-2015-0721 https://doi.org/10.1108/IJOPM-11-2015-0721 
Di Pietro, L, Mugion, R.G., \& Renzi, M.F. (2013). An integrated approach between Lean and customer feedback tools: An empirical study in the public sector. Total Quality Management \& Business Excellence, 24(7-8), 899-917. https://doi.org/10.1080/14783363.2013.791106

Fernández-González, A.J., Fernández-Pérez, R., \& Prado Prado, J.C. (2014). Personnel participation: A review of its role in Corporate Social Responsibility models and Standards. In Annals of Industrial Engineering 2012. Springer. http://www.springer.com/us/book/9781447153481

Fitzsimmons, J., \& Fitzsimmons, M. (2004). Service management: Operations, strategy, and information technology. London: McGraw-Hill/Irwin.

García-Lorenzo A., \& Prado-Prado J.C. (2002). La participación del personal en la mejora continua de las empresas. Madrid: AEC.

García-Arca, J., \& Prado-Prado, J.C. (2011). Systematic Personnel Participation for Logistics Improvement: A Case Study. Human Factors and Ergonomics in Manufacturing and Services Industries, 21(2), 209-223.

https://doi.org/10.1002/hfm.20246

García-Sabater, J.J., Marín-García, J.A., \& Perelló-Marín, M.R. (2012). Is implementation of continuous improvement possible? An evolutionary model of enablers and inhibitors. Human Factors and Ergonomics in Manufacturing \& Service Industries, 22(2), 99-112. https:/ / doi.org/10.1002/hfm.20262

Gerhart, B. (2012). Construct validity, causality, and policy recommendations: The case of high performance work practices systems. Human Resource Management Review, 22, 157-160.

http://www.sciencedirect.com/science/article/pii/S1053482211000738 https://doi.org/10.1016/j.hrmr.2011.12.002

Jaca, C., Santos, J., Errasti, A., \& Viles, E. (2012). Lean thinking with improvement teams in retail distribution: A case study. Total Quality Management \& Business Excellence, 23(4), 449-465(1).

https://doi.org/10.1080/14783363.2011.593907

Jaca, C., Viles, E., Mateo, R., \& Santos, J. (2012). Components of sustainable improvement systems: theory and practice. The TQM Journal, 24(2), 142-154 (2). https://doi.org/10.1108/17542731211215080

Jaca, C., Paipa-Galeano, L., Viles, E., \& Mateo, R. (2016). The impact of a readiness program for implementing and sustaining continuous improvement processes. The TQM Journal, 28(6), 869-886. https://doi.org/10.1108/TQM-08-2014-0067

Jurburg, D., Viles, E., Tanco, M., \& Mateo, R. (2016). What motivates employees to participate in continuous improvement activities? Total Quality Management \& Business Excellence , 1-20.

https://doi.org/10.1080/14783363.2016.1150170

Marín-García J.A., Pardo-Val M., \& Bonavía-Martín T. (2008). Longitudinal study of the results of continuous improvement in a company. Team Performance Management, 14, 55-69. https://doi.org/10.1108/13527590810860203

Marín-García, J.A., \& Bautista-Póveda, Y. (2010). The implementation of a continuous improvement project at a Spanish Marketing Company: A Case Study. International Journal of Management, 27(3), 593-606. http://www.upv.es/i.grup/repositorio/own/ART 2010 Marin\&Bautista IJM Continuous Improvement Project Full Pap er.pdf

Neumann, S.L., Mothersell, W.M., \& Motwani, J. (2015). The need for implementing lean in the public sector. International Journal of Business Excellence, 8(1), 104-121. https://doi.org/10.1504/IJBEX.2015.065982

Lam, M., O’Donnell, M., \& Robertson, D., (2015). Achieving employee commitment for continuous improvement initiatives. International Journal of Operations \& Production Management, 35(2), 201-215. https://doi.org/10.1108/IJOPM-03-2013-0134

Prado-Prado, J.C., Fernández-Pérez, R., \& Mosteiro-Añón, M. (2013). Design, Development and Implementation of Lean Management in Healthcare. Proceedings 22th International Conference on Production Research (ICPR). Brazil. 
Prado-Prado, J.C., García Arca, J., \& Fernández González, A. (2012). Competing Through People: A Model for the Implementation of Employee Participation Systems. Industrial Engineering: Innovative Networks, 181-189. Springer. https://link.springer.com/chapter/10.1007/978-1-4471-2321-7 21 https://doi.org/10.1007/978-1-4471-2321-7_21

Psomas, E.L., \& Jaca, C. (2016). The impact of total quality management on service company performance: evidence from Spain. International Journal of Quality \& Reliability Management, 33(3), 380-398.

https://doi.org/10.1108/IJQRM-07-2014-0090

Rapp C., \& Eklund J. (2007). Sustainable development of a suggestion system: Factors influencing improvement activities in a confectionary company. Human Factors in Ergonomics and Manufacturing, 17(1), 79-94.

https://doi.org/10.1002/hfm.20064

Scherrer-Rathje, M., Boyle, T.A., \& Deflorin, P. (2009). Lean Take Two! Reflection from the second attempt at lean implementation. Business Horizons, 52, 79-88. http://www.sciencedirect.com/science/article/pii/S0007681308001304 https://doi.org/10.1016/j.bushor.2008.08.004

Slack, N., Chambers, S., Harland, C., Harrison, A., \& Johnson, R. (2007). Operations management. London: Pearson Education Limited.

Terziovski, M., \& Sohal, A.S. (2000). The adoption of continuous improvement and innovation strategies in Australian manufacturing firms. Technovation, 20 (10), 539-550. https://doi.org/10.1016/S0166-4972(99)00173-X

Uhrin, Á., Bruque-Cámara, S., \& Moyano-Fuentes, J. (2017). Lean production, workforce development and operational performance. Management Decision, 55(1), 103-118. https://doi.org/10.1108/MD-05-2016-0281

Wang, T., Thornhill, S., \& Zhao, B. (2016). Pay-for-Performance, Employee Participation, and SME Performance. Journal of Small Business Management. https://doi.org/10.1111/jsbm.12268

Yin, R.K. (2002). Applications of Case Study Research. Thousands Oaks: Sage Publications.

Journal of Industrial Engineering and Management, 2018 (www.jiem.org)

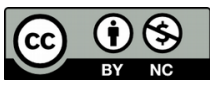

Article's contents are provided on an Attribution-Non Commercial 4.0 Creative commons International License. Readers are allowed to copy, distribute and communicate article's contents, provided the author's and Journal of Industrial Engineering and Management's names are included. It must not be used for commercial purposes. To see the complete license contents, please visit https://creativecommons.org/licenses/by-nc/4.0/. 